\title{
GESTÃO DE GASTOS EM SERVIÇOS DE DESENVOLVIMENTO E MANUTENÇÃO DE SOFTWARES
}

\section{EXPENSE MANAGEMENT IN SERVICES OF DEVELOPMENT AND MAINTENANCE OF SOFTWARES}

\author{
Ricardo Kenji Fonseca ${ }^{1}$ \\ ${ }^{1}$ Universidade do Estado de Santa Catarina - UDESC - Florianópolis - SC - Brasil \\ ricardokenji1@gmail.com \\ Fabiano Maury Raupp ${ }^{2}$ \\ ${ }^{2}$ Universidade do Estado de Santa Catarina - UDESC - Florianópolis -SC - Brasil \\ fabianoraupp@hotmail.com
}

\begin{abstract}
Resumo
O presente estudo apresenta os resultados da estruturação da gestão de gastos incorridos em uma empresa prestadora de serviços de desenvolvimento e manutenção de softwares. Trata-se de uma pesquisa descritiva, realizada por meio de um estudo de caso, com abordagem predominantemente qualitativa. Os dados foram coletados por meio de entrevistas semiestruturadas e documentos da organização, analisados por meio da técnica de análise descritiva. Considerando as características peculiares das empresas de serviços no que tange à contabilidade de custos, fez-se o diagnóstico da gestão de gastos adotada por esta empresa, a qual organiza suas atividades predominantemente por projetos (ordens de serviço). Analisou-se como era feita a classificação dos gastos da mesma, qual era sua composição e como ocorria a apropriação dos gastos desta empresa. Na sequência, elaborou-se uma proposta de gestão de gastos, visando amenizar deficiências identificadas na etapa de diagnóstico do modelo de gestão de gastos adotado pela empresa. A proposta de gestão de gastos foi baseada no custeio por absorção com departamentalização. Dessa maneira, buscou-se aprimorar o custeamento, o controle e o fornecimento de informações para a tomada de decisão.
\end{abstract}

Palavras-chave: gestão de gastos; serviços; desenvolvimento e manutenção de softwares.

\section{Introdução}

A realidade empresarial brasileira apresenta uma dualidade: ao mesmo tempo em que o número total de empresas ativas no país vem crescendo ano após ano, em conformidade com o desempenho positivo da economia, quase $50 \%$ das empresas que abrem as suas portas no Brasil terminam por encerrar suas atividades antes do terceiro ano de mercado (IBGE, 2010).

As empresas de serviços em Tecnologia da Informação (TI), por serem intensivas em conhecimento enfrentam um desafio particular: a questão da mão de obra e da legislação trabalhista no Brasil. Um estudo realizado em 2012 pela Associação para Promoção da Excelência do Software 
Brasileiro (SOFTEX), analisou a escassez da mão de obra especializada no setor de Tecnologia da Informação (TI) no Brasil e concluiu que o deficit de profissionais constatado em estudos anteriores não só se mantinha como tenderia a aumentar caso não fossem tomadas atitudes pró-ativas para a sua redução (SOFTEX, 2012).

Este setor, que empregava em 2011 mais de 400 mil pessoas, pagando salários 150\% superiores à média das empresas de serviços não financeiros (IBGE, 2011), apresentou boas taxas de crescimento de 2007 a 2010 - um crescimento real de $24,6 \%$ da receita operacional líquida (ROL) no período (IBGE, 2010) - cresceu também de 2010 para 2011 (comparando-se o resultado de ambas pesquisas do IBGE constatou-se aumento nominal de 19\% na ROL, superior a inflação do período) e apresenta ainda grandes expectativas de crescimento futuro. Para a Associação Brasileira das Empresas de Software (ABES), que publica anualmente um estudo com o panorama e as tendências para o mercado de software no Brasil, a edição de 2014 constatou que o mercado brasileiro de Softwares e Serviços cresceu em US\$25 bilhões, com crescimento de 10,1\% em relação ao ano anterior, um desempenho considerável, pois ainda que abaixo da média dos últimos nove anos (de 11,7\%) posicionou o Brasil entre os dez países com maior crescimento neste setor (a média mundial foi de 4,8\%) (ABES, 2014).

Considerando que muitas dessas empresas, especialmente as que prestam serviços de desenvolvimento de software sob encomenda, costumam organizar as suas atividades por meio de projetos, destaca-se a importância no alinhamento entre as metodologias de gerenciamento de projetos e a gestão de gastos da empresa. Isto porque as metodologias de gerenciamento de custos de projeto utilizam parâmetros de custo como informações de entrada. Parâmetros como, por exemplo, o valor da hora trabalhada, que são fornecidos pelo departamento de custos da empresa. Essas informações, estando incorretas, comprometem todo o acompanhamento de custo realizado posteriormente. Um projeto que aparentemente tenha finalizado dentro dos padrões de custos estabelecidos, pode na verdade ter tido uma rentabilidade negativa caso os parâmetros de custo por hora tenham sido subavaliados.

Diante do cenário apresentado, evidencia-se a necessidade de sistemas de informações confiáveis para que a gestão empresarial possa embasar sua tomada de decisão de maneira a preservar a competitividade no mercado. Como observado por Marion (2007), apesar de as adversidades macroeconômicas brasileiras representarem um grande desafio para as empresas, muitas vezes a causa do insucesso está mais relacionada com a tomada de decisões. A gestão de gastos da empresa pode apoiar-se na contabilidade de custos para, de maneira adequada, estabelecer quais custos competem a cada bem produzido ou serviço prestado. Contribui para que a empresa identifique a lucratividade de seus produtos e fornece insumos para a precificação, além da média de preços praticados no mercado, que em muitos casos (DUARTE, 2009) é o único fator 
considerado na formulação de preços. Para tanto, o objetivo do estudo consistiu em estruturar a gestão de gastos incorridos em uma empresa prestadora de serviços de desenvolvimento e manutenção de softwares.

Procurou-se contribuir com a bibliografia relativa a gestão de gastos em empresas prestadoras de serviços que trabalham por projetos, especificamente no caso das de desenvolvimento e manutenção softwares. Evidenciou-se, durante a etapa de levantamento bibliográfico, uma lacuna na área de conhecimento em termos de estudo que tratam deste tema específic - à época, haviam sido identificados poucos estudos acadêmicos, sendo que destes, alguns analisaram a implantação do $\mathrm{ABC}$ para a gestão de custos em empresas desenvolvimento de software e de serviços em informática (BRAGA, 2009; CORRÊA, 2002; CRUZ, 2011; GOMES, 2004; SOUZA, 2002) e outros trataram de pesquisas exploratórias que buscaram identificar as metodologias utilizadas pelas empresas de desenvolvimento de software das regiões de estudo para a gestão de seus custos (CLEMENTE; SOUZA, 2005; MARINHO, 2011).

\section{Fundamentação teórica}

\subsection{A contabilidade de custos e suas funções}

Impulsionada pela evolução tecnológica e pelo crescimento das empresas - com o surgimento das grandes corporações: dispersas geograficamente, diversificadas em termos de negócios e cujos donos do capital encontravam-se cada vez mais afastados das operações - a Contabilidade de Custos também se desenvolveu ao longo desses séculos (OLIVEIRA, 2009), de maneira que passou a desempenhar funções até mais estratégicas que a sua finalidade original de avaliação de estoques, para também a fornecer informações para a administração, inclusive em empresas não industriais (MARTINS, 2003).

A Contabilidade de Custos assumiu um papel importante na gestão de gastos (no âmbito da Contabilidade Gerencial), desempenhando duas novas funções relevantes: a de controle e a de auxílio às tomadas de decisão. Segundo Martins (2003), no que diz respeito a controle, a Contabilidade de Custos fornece os dados para o planejamento de gastos (estabelecimento de padrões, orçamentos e outras formas de previsão), para, posteriormente, avaliar o desempenho pela comparação do resultado efetivado com o planejado. No auxílio à tomada de decisão, Martins afirma (2003) que o papel da Contabilidade de Custos está em fornecer informações relevantes e confiáveis com relação ao custo de produtos ou serviços, permitindo a análise de sua composição, das estratégias para a sua redução e apoiando, a curto e a longo prazo, decisões relacionadas com: a introdução ou corte de produtos/serviços (rentabilidade); preços; produção versus terceirização, dentre outras. 
Apesar do surgimento da contabilidade de custos estar relacionado às empresas industriais, sua aplicação também é notável para a as empresas prestadoras de serviços, devido tanto à sua função de avaliação de estoques - para aquelas empresas que trabalham com estoques de serviços em andamento - quanto à sua função gerencial de controle e de auxílio à tomada de decisão. Consequentemente, é hoje relativamente comum encontrarmos Bancos, Financeiras, Lojas Comerciais, Escritórios de Planejamento, de Auditoria, de Consultoria, utilizando-se de Contabilidade de Custos (MARTINS, 2003). Portanto, ressalta-se que todos os conceitos e problemáticas que serão apresentadas a seguir, têm perfeita aplicação para a gestão de gastos de empresas de serviços (MARTINS, 2003), apesar de na maioria das bibliografias consultadas terem sido apresentadas com enforque na aplicação em empresas industriais.

\subsection{Nomenclaturas}

Entende-se como gestão de gastos para os fins deste trabalho todo o conjunto de processos e atividades relacionadas com a organização, o planejamento, o controle e a avaliação de gastos. Martins (2003), Hansen e Mowen (2003) atribuem a um conceito semelhante o termo gestão de custos, enquanto Horngren, Datar e Foster (2004) utilizam o termo administração de custos. Adicionalmente, Martins (2003, p. 297) apresenta também o termo gestão estratégica de gastos para “designar a integração que deve haver entre o processo de gestão de custos e o processo de gestão da empresa como um todo."

Neste caso específico, apoiando-se nos conceitos para administração, gerenciamento e gestão apresentados por Valeriano (2005), optou-se pelo termo gestão porque este representaria um nível mais especializado no que tange à administração dos recursos financeiros da organização (limitando-se apenas à gestão dos gastos, mas não deixando de fornecer insumos para outros níveis da administração). O termo gasto, por sua vez, foi escolhido por ser mais abrangente do que simplesmente custo: engloba também a gestão das despesas e dos investimentos.

Para convergência de entendimento estes termos são definidos a seguir, utilizando-se como principal fonte de referência as definições apresentadas por Martins (2003): Gasto: qualquer sacrifício financeiro decorrente da aquisição ou utilização de um bem ou serviço; Desembolso: pagamento de um gasto, extinguindo a obrigação financeira originada por este e podendo ocorrer antes, depois ou juntamente ao mesmo; Custo: gasto relativo a um bem ou serviço utilizado na prestação de serviços; Despesa: gasto relativo a um bem ou serviço utilizado para o funcionamento da empresa (Gastos administrativos, financeiros e com vendas são despesas); e Investimento: Gasto relativo a um bem ou serviço que passa a compor o Ativo da empresa.

Custos e despesas, por sua vez, também podem ser subclassificados quanto às suas características. Para os fins deste estudo, diferenciam-se os custos diretos dos indiretos e os custos 
ou despesas fixas das variáveis. A primeira classificação se dá "quanto à forma e ao critério de identificação e apropriação [dos custos] aos diversos bens e serviços produzidos simultaneamente" (OLIVEIRA, 2009, p. 63). A segunda, que para Martins (2003) é a classificação mais importante de todas, tem por base a relação de proporcionalidade entre o valor total do custo ou da despesa e o volume de produção ou de geração de receitas, respectivamente. Sendo assim, a definição de tais termos é apresentada no Quadro 1.

\begin{tabular}{|c|c|}
\hline \multicolumn{2}{|r|}{ Quadro 1-Classificações de custos e despesas } \\
\hline Termo & Definição \\
\hline Custo direto & $\begin{array}{l}\text { "Custos que podem ser quantificados e identificados aos produtos ou serviços e valorizados com relativa } \\
\text { facilidade [...] não necessitam de rateio para serem alocados aos [...] serviços prestados [...] geralmente } \\
\text { facilmente identificados aos produtos (OLIVEIRA, 2009, p. 70). "Podem ser rastreados ao objeto de } \\
\text { custo de forma economicamente viável (eficaz)" (HORNGREN; DATAR; FOSTER, 2004, p. 26). } \\
\text { "Podem ser diretamente apropriados aos produtos, bastando haver uma medida de consumo" (MARTINS, } \\
\text { 2003, p. 48). }\end{array}$ \\
\hline Custo indireto & $\begin{array}{l}\text { "São aqueles custos que, por não serem perfeitamente identificados nos produtos ou serviços, não podem } \\
\text { ser apropriados de forma direta para as unidades específicas, ordens de serviço ou produtos, serviços } \\
\text { executados etc. Necessitam portanto, da utilização de algum critério de rateio para sua alocação" } \\
\text { (OLIVEIRA, 2009, p. 73). "São aqueles custos que não são facilmente identificados com o objeto de } \\
\text { custo" (LEONE, 2009, p. 35). "Não oferecem condição de medida objetiva e qualquer tentativa de } \\
\text { alocação tem de ser feita de maneira estimada, muitas vezes arbitrária" (MARTINS, 2003, p. 49). }\end{array}$ \\
\hline Custos fixos & $\begin{array}{l}\text { "São aqueles que permanecem constantes dentro de determinada capacidade instalada, } \\
\text { independentemente do volume de produção. Consequentemente, não são identificados como custos da } \\
\text { produção do período, mas como custos de um período de produção." Permanecem constantes dentro de } \\
\text { determinado volume de produção (produção normal), seu valor por unidade produzida é diluído quanto } \\
\text { maior for o volume de produção. A alocação aos departamentos os centros de custos, na maioria das } \\
\text { vezes necessita de critérios de rateio determinados pela administração (OLIVEIRA, 2009, p. 64-65). } \\
\text { "Custo que permanece inalterado no total por um dado período de tempo, apesar de mudaç̧as no nível } \\
\text { relativo de atividade ou volume total" (HORNGREN; DATAR; FOSTER, 2004, p. 501). }\end{array}$ \\
\hline Custos variáveis & $\begin{array}{l}\text { "São aqueles custos que mantêm uma relação direta com o volume de produção ou serviço e, } \\
\text { consequentemente, podem ser identificados com os produtos. [...] o total dos custos variáveis cresce a } \\
\text { medida que o volume de atividades da empresa aumente" (OLIVEIRA, 2009, p. 68). } \\
\text { "Custo que muda no total em proporção as mudanças no nível relativo de atividade ou volume total" } \\
\text { (HORNGREN; DATAR; FOSTER, 2004, p. 501). }\end{array}$ \\
\hline Despesas fixas & $\begin{array}{l}\text { Semelhantes aos custos fixos, "são aquelas despesas que permanecem constantes dentro de determinada } \\
\text { faixa de atividades geradoras de receitas, independente do volume de vendas ou de prestação de serviços" } \\
\text { (OLIVEIRA, 2009, p. 68). }\end{array}$ \\
\hline Despesas variáveis & $\begin{array}{l}\text { "São aquelas que variam proporcionalmente às variações no volume das receitas" (OLIVEIRA, 2009, p. } \\
\text { 70). Ex: impostos sobre o faturamento e comissão de vendedores. }\end{array}$ \\
\hline $\begin{array}{l}\text { Gastos semifixos } \\
\text { ou semivariáveis }\end{array}$ & $\begin{array}{l}\text { Custos ou despesas que apresentam uma parcela fixa e outra variável, como podem ser os custos com } \\
\text { telecomunicações quando existe uma franquia e a cobrança por excedentes. É semifixo quando a parcela } \\
\text { fixa é maior, do contrário é semivariável. (OLIVEIRA, 2009). }\end{array}$ \\
\hline
\end{tabular}

Fonte: Elaboração própria (2014).

Adotou-se o entendimento que alocação e apropriação são sinônimos, representando a distribuição de custos (diretos ou indiretos) aos objetos de custos específicos. Apesar de Horngren, Datar e Foster (2004, p. 27) terem definido que apropriação é a "distribuição de custos indiretos para um objeto de custo em particular", não foi esse o tratamento dado por Oliveira (2009) nem por Martins (2003).

\subsection{Custeio por absorção}

O custeio por absorção consiste na alocação de todos os custos à produção do período 
(MARTINS, 2003). Pode-se dizer que o objeto de custo "absorve" todos os custos da produção, sejam diretos ou indiretos, fixos ou variáveis. Como ponto positivo, é o método de custeio adotado pela legislação comercial e fiscal brasileira, pois deriva dos Princípios De Contabilidade Geralmente Aceitos (OLIVEIRA, 2009), portanto com a sua adoção não há necessidade de custeamentos paralelos. Dessa maneira, e também por ser mais simples, é o sistema que apresenta o menor custo de implantação (MAHER, 2001). Como ponto negativo destaca-se que este utiliza frequentemente rateios arbitrários que, apesar de aparentemente lógicos, podem resultar em valores enganosos de custo para os produtos ou serviços, quanto mais representativa for a parcela de custos indiretos.

Martins (2003) apresenta o custeio por absorção organizado de duas maneiras distintas, com ou sem a utilização de departamentos na alocação dos custos. $\mathrm{Na}$ primeira abordagem, todos os custos indiretos, após identificados, são rateados aos produtos com base em critérios de rateio específicos.

Com a departamentalização, esses custos, antes de serem alocados aos produtos, são alocados primeiramente aos departamentos, por meio de rateios ou do rastreamento (custos indiretos dos produtos, podem ser diretos com relação aos departamentos). Os custos dos departamentos de produção, que trabalham diretamente nos bens ou que prestam efetivamente os serviços, podem ser rateados aos produtos de maneira razoavelmente aceitável, tendo por base as horas de mão de obra direta dedicadas a cada produto, por exemplo. Entretanto, nos demais departamentos este tipo de rateio seria completamente arbitrário. Portanto, antes de serem alocados aos produtos, os custos destes departamentos são apropriados entre os próprios departamentos, por meio de critérios que indiquem o quanto cada departamento esteve "a serviço" de outro.

Martins (2003) sugere que esta distribuição de custos ocorra de maneira hierarquizada: dos departamentos que têm menor para os que têm maior relação com a produção. Dessa forma, um departamento que já tenha tido seus custos distribuídos não recebe custo de nenhum outro, evitando-se uma situação de alocação reflexiva, que além de mais complexa e trabalhosa, muitas vezes necessita do auxílio de softwares para ser resolvida. Consequentemente, os custos são sucessivamente distribuídos entre os departamentos de apoio e os de produção, até que estes últimos concentrem todos os custos indiretos, para que se possa fazer o rateio para a produção.

Observa-se que com a departamentalização são reduzidos os impactos negativos do rateio dos custos indiretos no custeio por absorção, visto que existe uma racionalidade maior na distribuição desses custos. Para Oliveira (2009), a departamentalização permite também responsabilizar cada departamento por seus custos, conhecer o custo total dos mesmo e avaliar o seu desempenho e eficiência. Em contrapartida, o sistema torna-se mais complexo, de maneira que é preciso considerar-se o custo-benefício dessa abordagem em cada situação. 
A respeito dos critérios de rateio, havendo ou não departamentalização, destaca-se que o custo indireto total pode ser alocado com base em poucos ou em múltiplos critérios de rateio. De maneira geral, quanto menos critérios forem adotados, maior será a simplificação e menor será a qualidade dos dados gerados (MARTINS, 2003). Deve-se neste caso observar a materialidade (relevância) de cada item de custo indireto, assim como a validade de cada critério de rateio. Adicionalmente, Martins (2003) aponta para a diferenciação entre o rateio por uso e potencial de uso (custos fixos).

\section{Procedimentos metodológicos}

A pesquisa empreendida foi considerada quanto aos objetivos, quanto aos procedimentos e quanto à abordagem do problema. Quanto aos objetivos, trata-se de uma pesquisa descritiva. De acordo com Malhotra (2005), este é o tipo de pesquisa que: baseado em uma declaração clara do problema e em hipóteses específicas, decorrentes de um conhecimento prévio do assunto, tem como principal objetivo a descrição do objeto de estudo. Neste caso, o objeto de estudo foi a gestão de gastos de uma pequena empresa de desenvolvimento de softwares.

Em relação aos procedimentos, a pesquisa classifica-se como um estudo de caso. O Estudo de caso é a pesquisa em profundidade, que analisa detalhadamente um ou poucos elementos da população (VERGARA, 2003), levantando muitas informações a seu respeito, mas sem, entretanto, permitir qualquer generalização para toda a população, visto o tamanho da amostra não é representativo. Desta maneira, a presente pesquisa analisou a gestão de gastos de uma empresa específica. Como a análise limitou-se apenas a esta empresa, suas conclusões não permitem qualquer inferência quanto à gestão de gastos de outras empresas do mesmo gênero nesta ou em outras regiões e, similarmente, considera-se que o modelo de gestão de gastos proposto aplica-se somente à mesma. Sua adoção em qualquer outra empresa poderia ser objeto de um estudo de caso próprio.

No tocante à abordagem da pesquisa, trata-se de um estudo com abordagem predominantemente qualitativa. Esta é a abordagem preponderante entre estudos de caso, visto que dela resulta em um detalhamento mais completo de cada objeto de estudo do que seria obtido pela abordagem quantitativa, ainda que mais subjetivo. Kirk e Miller (1986) definem que esta é a abordagem que busca identificar a presença ou ausência de algo.

Entrevistas semiestruturadas foram realizadas com os responsáveis pela administração financeira da empresa. Os documentos utilizados pela gestão de gastos foram consultados. Por fim, fez-se também a observação da execução dos processos. No processo de detalhamento do modelo de gestão de gastos adotado pela empresa, a análise das informações levantadas nas entrevistas, nos documentos, e na observação da execução das atividades foi realizada por meio da análise 
descritiva.

\section{Descrição e Análise dos Resultados}

\subsection{Diagnóstico da gestão de gastos}

À época de realização do estudo, a empresa fazia parte de uma holding com empresas com mais de dez anos de existência, todas voltadas para o ramo digital. Ativa no mercado desde 2009, contava com mais de cinquenta colaboradores, dentre celetistas, estagiários e prestadores de serviços (PJs) e um faturamento anual superior a $\mathrm{R} \$ 3$ milhões. Foi classificada como uma pequena empresa, segundo o critério adotado pelo Banco Nacional do Desenvolvimento (BNDES, 2014). Seus serviços principais eram de desenvolvimento e de manutenção de softwares, os quais eram prestados exclusivamente às empresas da holding da qual fazia parte.

Constatou-se na etapa inicial do estudo que a gestão de gastos da empresa já estava em processo de reorganização. Até final de 2013 não havia integração entre a gestão contábil e a financeira, esta última fazia apenas o controle dos pagamentos pelo fluxo de caixa e enviava mensalmente todas as movimentações para que a primeira fizesse o encerramento contábil. Não havia apropriação dos custos aos serviços prestados. Mensalmente, todos os gastos eram rateados às empresas da holding, tendo como principais bases de rateio a utilização da mão de obra direta e o seu valor por dia de trabalho.

Ao longo de 2014 foram implantadas melhorias importantes para o processo de custeamento dos serviços. Com base nos balancetes do primeiro semestre de 2014, fez-se um levantamento de todos os gastos contabilizados neste período, identificando as categorias de gastos pela classificação adotada pela contabilidade da empresa. As Tabelas 1 e 2 apresentam o resultado deste levantamento, com a representatividade de cada gasto sobre o valor total da empresa e um detalhamento dos itens que compõem os gastos.

Tabela 1 - Levantamento de gastos: custos de janeiro a junho de 2014

\begin{tabular}{lcl}
\hline \multicolumn{1}{c}{ Categoria do gasto } & $\%$ dos gastos & \multicolumn{1}{c}{ Observações } \\
\hline Salários e ordenados & $38,34 \%$ & Apurado com base na folha de pagamentos. \\
Pró labore & $3,07 \%$ & Remuneração dos sócios pelo trabalho basicamente administrativo. \\
Prêmios de gratificações & $16,72 \%$ & Compõem a remuneração bruta dos funcionários. \\
$1^{\circ}$ salário & $5,31 \%$ & Provisionamento para pagamento de 13. \\
Férias & $7,50 \%$ & Provisionamento de férias. \\
INSS & $5,39 \%$ & Encargos sociais sobre a folha de pagamentos e provisões de férias e $13^{\circ}$. \\
FGTS & $6,03 \%$ & FGTS sobre salários, gratificações, provisão de férias e $13^{\circ}$ e rescisões. \\
Bolsa estágio & $0,59 \%$ & Valor das bolsas de estágio. \\
Transportes de empregados & $0,11 \%$ & Parcela do empregador sobre o vale-transporte. \\
Alimentação de empregados & $3,48 \%$ & Pagamento de vales-alimentação e refeição e suas respectivas taxas. \\
Assistência médica & $0,00 \%$ & O valor é descontado integralmente do empregado. \\
Assistência médica e social & $0,01 \%$ & Atestados admissionais, demissionais e periódicos.
\end{tabular}




\begin{tabular}{lll} 
Água & $0,18 \%$ & Rateio da conta de água do prédio entre todas os locatários. \\
Comunicação & $0,48 \%$ & Internet e telefonia. \\
Energia elétrica & $0,43 \%$ & Consumo de energia conforme conta de luz de cada sala comercial. \\
Seguros & $0,12 \%$ & Seguro de incêndio e de vida para os funcionários. \\
Serviço de terceiros & $4,20 \%$ & Remuneração de colaboradores PJ. \\
Alugueis & $4,64 \%$ & Valor de aluguel de oito salas comerciais. \\
Depreciação & $0,33 \%$ & Depreciação de equipamentos, em geral computadores e periféricos. \\
Amortização & $0,04 \%$ & Amortização do uso de softwares do ativo imobilizado \\
\hline
\end{tabular}

Fonte: Dados da pesquisa (2014).

Percebe-se que todos os gastos referentes a aluguéis, energia e água, por exemplo, foram alocados a produção. Entretanto, sabia-se que parte destes custos também deveriam ser alocados ao departamento administrativo. Similarmente, toda mão de obra foi considerada custo, quando uma parcela desta deveria ser classificada como despesa.

Tabela 2 - Levantamento de gastos: despesas de janeiro a junho de 2014

\begin{tabular}{lrl}
\hline \multicolumn{1}{c}{ Categoria do gasto } & \% dos gastos & \multicolumn{1}{c}{ Observações } \\
\hline Aluguéis de equipamentos & $0,03 \%$ & Gasto locação do filtro de água potável. Comum a todos. \\
IPTU & $0,45 \%$ & Referente ao aluguel das salas comerciais. \\
Taxas diversas & $0,01 \%$ & \\
Multas de mora & $0,04 \%$ & \\
Contribuição sindical patronal & $0,01 \%$ & Contribuição anual obrigatória ao sindicato das empresas (SEINFLO). \\
I.O.F & $0,01 \%$ & Decorrente do raro uso do cheque especial. \\
Bens de uso permanente & $0,72 \%$ & Compra de itens de baixo valor. \\
Despesas postais e telegráficas & $0,00 \%$ & \\
Material de expediente & $0,02 \%$ & Material de escritório. \\
Material de higiene e limpeza & $0,06 \%$ & \\
Honorários contábeis & $1,10 \%$ & \\
Serviços prestados por terceiros & $0,20 \%$ & Serviços prestados à empresa por outras pessoas jurídicas. \\
Material de consumo & $0,10 \%$ & Material de copa e cozinha. \\
Mensalidades e anuidades & $0,02 \%$ & Taxa de manutenção do plano de saúde dos funcionários. \\
Viagens aéreas & $0,02 \%$ & \\
Manutenção e reparo & $0,12 \%$ & Serviços eventuais de manutenção de equipamentos. \\
Juros passivos & $0,01 \%$ & \\
Juros e comissões bancárias & $0,10 \%$ & \\
\hline Fonte: Dados da pesquisa $(2014)$. &
\end{tabular}

Fonte: Dados da pesquisa (2014).

Os gastos eram custeados às empresas da holding (clientes) e, na maioria dos casos, esta alocação se dava por meio de rateio. Eram utilizados essencialmente dois critérios que tinham por base os apontamentos de trabalho da mão de obra direta. O primeiro critério era a quantidade de trabalho da mão de obra direta dedicado a cada cliente (em dias até meados de julho/2014 e em horas posteriormente). Deste, resultava a base utilizada para ratear aqueles gastos que, em geral, ou seriam maiores ou deveriam ser apropriados em maior quantidade quanto maior fosse o número de pessoas dedicadas a determinada empresa, independente da remuneração destas pessoas. Uma empresa que demandasse uma quantidade maior de dias de trabalho, por exemplo, receberia mais custos de aluguel e auxílio-alimentação, mesmo que o pessoal demandado fosse o de menor remuneração. Os gastos rateados às empresas clientes, segundo este critério, eram: Custos: Pró labore, Bolsa estágio, Transportes de empregados, Alimentação de empregados, Assistência médica 
e social, Custos com utilidades e serviços, Água, Comunicação, Energia elétrica, Seguros, Demais custos, Alugueis, Depreciação e Amortização; Despesas: Viagens aéreas, Manutenção e reparo, Aluguéis de máquinas e equipamentos, Impostos, taxas e contribuições, IPTU, Taxas diversas, Multas de mora, Despesas gerais, Bens de uso permanente, Despesas postais e telegráficas, Material de expediente, Material de higiene e limpeza, Honorários contábeis, Serviços prestados por terceiros, Material de consumo e Mensalidades e anuidades.

O segundo critério era o valor do trabalho da mão de obra direta que fosse demandado pelas empresas. O cálculo era relativamente simples: dividia-se a remuneração líquida do mês de referência (desconsiderando o recebimento de férias), pelo volume total de trabalho apontado pelo colaborador (em dias ou em horas), resultando em uma taxa monetária por unidade de trabalho. O trabalho identificado a cada empresa cliente era então multiplicado por esta taxa e a soma do valor de todo trabalho apontado resultava nesta base de rateio, que era utilizada para alocar aqueles gastos que apresentavam relação com a remuneração. A lógica por trás deste rateio era que empresas que demandassem uma mão de obra mais onerosa, receberiam um custo maior de salários, gratificações e provisões trabalhistas, por exemplo. Entretanto, constatou-se que o valor rateado não era igual ao somatório de todos os recebimentos líquidos de salário utilizado para o cálculo da base de rateio.

As despesas financeiras também eram apropriadas segundo este critério, pelo raciocínio de que os gastos decorrentes da falta de recursos financeiros, em determinados momentos, deveriam ser atribuídos ao item de maior representatividade nos gastos da empresa, o qual era justamente o gasto com a mão de obra.

Adicionalmente, constatou-se contribuição sindical patronal era indevidamente rateada por esse critério, pois havia-se confundido com a contribuição sindical que era descontada dos funcionários, equivalente ao valor de um dia de trabalho por ano. Os gastos rateados às empresas clientes segundo este critério eram: Custos: Salários e ordenados, Prêmios de gratificações, $13^{\circ}$ salário, Férias, INSS, FGTS; Despesas: Contribuição sindical patronal, I.O.F, Juros passivos, Desconto concedidos, Juros de mora, Juros e comissões bancárias.

\subsection{Proposta de gestão de gastos}

O diagnóstico da gestão de gastos revelou que a estrutura adotada anteriormente, apesar do aperfeiçoamento nos últimos anos, ainda não atendia de maneira satisfatória todas as suas funções. Sendo assim, elaborou-se uma proposta para a gestão de gastos da empresa. Inicialmente trabalhouse a readequação da classificação de gastos. Na sequência, foi apresentada uma nova forma apuração do valor da mão de obra direta, para então discorrer sobre a sua alocação aos serviços prestados, aos projetos internos e aos departamentos. Em seguida, analisou-se uma nova abordagem para a distribuição dos custos fixos, para então apresentar um modelo de apropriação dos gastos da 
empresa, com custeio dos serviços prestados. Por fim, discorreu-se sobre a questão do controle e do fornecimento de informações para a tomada de decisão resultante da implantação desta proposta de gestão de gastos.

\subsubsection{Classificação dos gastos}

Na classificação proposta levou-se em consideração que os gastos relativos à remuneração do pessoal apresentavam uma parcela de despesa, composta pela remuneração do pessoal exclusivamente administrativo - incluindo os sócios - adicionada da parcela referente ao trabalho do pessoal da produção em projetos internos da empresa, apurada com base nos apontamentos de hora. Os gastos da categoria "utilidades e serviços" e o aluguel das salas comerciais, também deveriam ter parcela considerada como despesa. Esta separação poderia ser realizada utilizando-se uma combinação do número de postos de trabalho e da área ocupada por departamento para o aluguel e um rateio com base neste resultado para as contas de água e de energia elétrica, visto que estes gastos podiam ser rastreados às salas. Nos gastos com comunicação, a parcela de custo ou despesa do gasto com internet poderia ser estabelecida com base no número de pessoas que tinham acesso à mesma, na produção ou fora dela, respectivamente. Já os gastos com telefonia seriam classificados integralmente como despesa, visto que não tinham relação com a produção. O mesmo tratamento seria dado aos gastos com seguros, amortizações e depreciações. A única despesa que teria uma parcela reconhecida como custo era o gasto com IPTU, cuja divisão em custo ou despesa poderia utilizar os mesmos critérios utilizados para o gasto com aluguel.

Os itens que compunham a remuneração da mão de obra (própria e de terceiros) e os encargos sobre a mesma foram classificados como fixos e variáveis. Pela proposta de classificação, estes gastos devem ser divididos em três parcelas distintas: Parcela de custo direto: gastos apropriados em função do apontamento de horas na prestação dos serviços; Parcela de custo indireto: gastos relativos às horas não produtivas da mão de obra direta (rateadas aos serviços prestados em função das horas dedicadas a cada projeto, por pessoa) e horas não rastreáveis aos serviços prestados especificamente (sendo rateadas aos mesmos com base na utilização das horas dos departamentos), por exemplo, as horas da gerência e as horas de reuniões do departamento; Parcela de despesa: gastos apropriados em função do apontamento de horas em projetos internos e demais horas não apontadas do pessoal administrativo.

Apesar de não comporem os gastos com remuneração, os valores com o transporte e alimentação dos empregados teriam a mesma abordagem que os gastos anteriores, visto que eram perfeitamente rastreáveis aos trabalhadores e, portanto, poderiam ser apropriados aos serviços prestados com relativa facilidade. O pró-labore deixou de ser apropriado aos serviços prestados para ser tratado exclusivamente como uma despesa, visto que à época os sócios não tinham 
envolvimento direto com a produção. A assistência médica e social também passou a ser tratada como despesa. Já o item assistência médica - plano de saúde não era um gasto efetivo da empresa, visto que era um benefício descontado integralmente dos empregados (a vantagem estava nos preços mais competitivos dos planos pelo desconto em folha e o único custo para a empresa era uma mensalidade pela administração dos planos que entra nas despesas administrativas). demais itens continuariam sendo considerados despesas, assim como era realizado anteriormente, recebendo apenas a classificação de despesa fixa, visto que eram gastos que não tinham relação com a produção e que permaneceriam os mesmos independentemente do volume de receitas. A diferença com relação à gestão de gastos anterior era que estes itens não seriam mais custeados aos clientes.

\subsubsection{Apropriação dos gastos com mão de obra}

Seguindo as orientações de Martins (2003 p. 133), o primeiro passo na proposta de uma nova metodologia para o cálculo do valor da hora da mão de obra direta seria estimar o custo anual de colaborador, considerando-se o salário recebido nos meses de trabalho, os direitos sobre férias, $13^{\circ}$ salário e abono pecuniário, o gasto com FGTS e outros encargos sociais sobre toda esta remuneração, uma provisão de FGTS rescisório e a estimativa de gastos com benefícios, como auxílio-alimentação e vale-transporte, que seriam pagos no decorrer do ano. Em seguida, seria projetado o total de horas que cada colaborador estaria à disposição da empresa, levando-se em conta os períodos de férias e eventuais afastamentos. A divisão deste custo anual pelo total de horas do colaborador resultaria na taxa que seria utilizada para a alocação da mão de obra direta aos departamentos, projetos e clientes. Vislumbrou-se que esta taxa não poderia ser única para o ano inteiro, devendo ser revisada mensalmente para ajustar variações do orçamento de horas e dos valores da remuneração. Esta taxa seria utilizada para determinar tanto o custo com mão de obra direta, quanto o custo indireto das horas não produtivas de cada colaborador, as quais poderiam ser identificadas subtraindo-se o total de horas apontadas aos projetos pelo colaborador das horas de trabalho registradas pelo sistema de ponto eletrônico. $\mathrm{Na}$ aplicação da proposta de apropriação dos gastos com mão de obra para os gastos do mês de agosto de 2014, foram considerados apenas os gastos projetados até o final daquele ano no cálculo do custo por hora de cada colaborador, conforme Figura 1. 
Figura 1 - Projeção do custo por hora de trabalho - agosto/2014

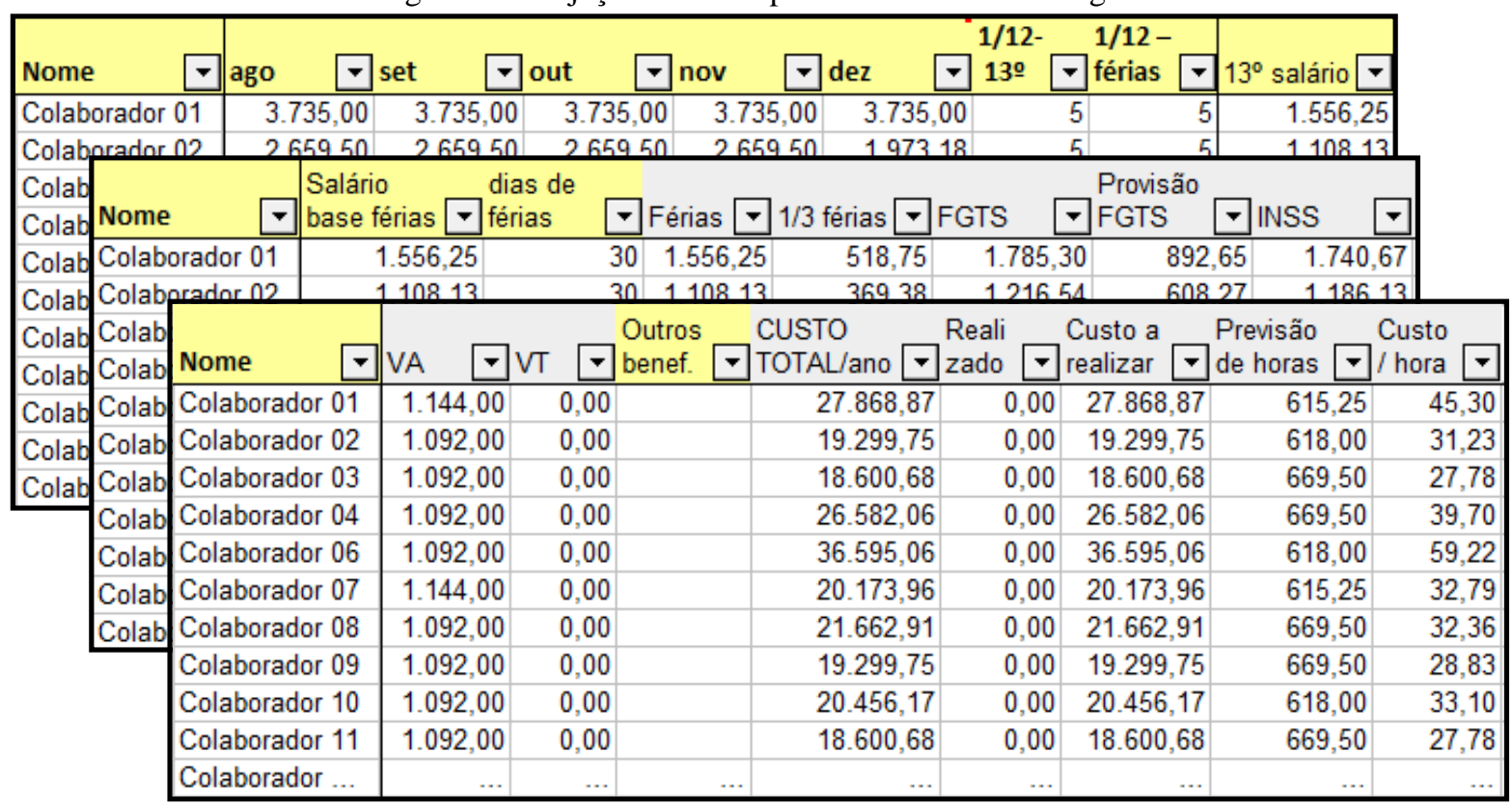

Fonte: Dados da pesquisa (2014).

Como se pode observar, foram consideradas as remunerações brutas até o final do ano; em média, cinco parcelas de provisões para o pagamento de $13^{\circ}$ salário e de férias; as provisões de FGTS e INSS sobre essas remunerações; e os gastos com benefícios até o final do ano. A soma destes valores resultou no custo total previsto para cada colaborador no período de agosto a dezembro, o qual dividido pela previsão de horas disponíveis neste mesmo período resultou no custo direto por hora trabalhada de cada um. Em média, este valor foi de R\$38,76/hora.

\subsubsection{Apropriação dos gastos aos departamentos}

O gasto total de um departamento seria composto pelo somatório do gasto com mão de obra direta e indireta (com relação aos projetos), mais os gastos apropriados de telecomunicações e aqueles decorrentes do uso da estrutura física da empresa (denominados de gastos ocupacionais). Diretamente identificáveis aos departamentos, o valor das horas de trabalho (produtivas ou não) dos integrantes dos departamentos e a remuneração dos gerentes de cada departamento. Indiretamente alocado aos departamentos, ainda com relação à mão de obra, a remuneração da diretoria, a qual pode ser rateada aos departamentos em função do número de colaboradores em cada departamento abrangido pela diretoria. O gasto com telecomunicações (internet) também seria rateado segundo este critério.

Por meio da análise da disposição física dos departamentos pode ser feita a separação da parcela dos gastos ocupacionais (aluguel, IPTU, água e luz) entre os departamentos. O valor referente às áreas comuns seria classificado como despesa. Como o departamento de suporte técnico possuía uma sala própria, o gasto ocupacional poderia ser identificado nas contas de luz e de 
aluguel (que trazia também o valor de água e IPTU). O gasto restante seria rateado entre os demais departamentos, com base no número de colaboradores de cada um. No estudo realizado para o mês de agosto, o gasto total apropriado aos departamentos foi de $\mathrm{R} \$ 229.701,75$, conforme demonstrado na Tabela 3.

Tabela 3 - Apropriação de gastos aos departamentos - agosto/2014

\begin{tabular}{l|c|c|r}
\hline Departamentos & Gasto total & Colaboradores & Gasto médio / colaborador \\
\hline Administrativo & $4.828,87$ & 2 & $2.414,44$ \\
Desenvolvimento de Sistemas & $86.665,81$ & 11 & $7.878,71$ \\
Desenvolvimento Web & $28.483,81$ & 5 & $5.696,76$ \\
Design & $33.943,21$ & 6 & $5.657,20$ \\
Manutenção de sistemas & $20.941,10$ & 6 & $3.490,18$ \\
Marketing & $11.952,44$ & 3 & $3.984,15$ \\
Suporte ao cliente & $42.886,50$ & 9 & $4.765,17$ \\
\hline Total & $229.701,75$ & 42 & $5.469,09$ \\
\hline
\end{tabular}

Fonte: Dados da pesquisa (2014).

Observa-se que os departamentos que apresentaram o maior gasto médio por colaborador e que, somados, receberam mais gastos, foram os departamentos de desenvolvimento web e de sistemas, atividade-fim da empresa.

\subsubsection{Custeamento dos projetos e clientes}

A apropriação dos gastos fixos aos departamentos permitiria o seu rateio aos projetos, com base na utilização da mão de obra direta do departamento. Estes gastos, somados aos valores dos apontamentos de trabalho e ao rateio das horas não produtivas da mão de obra direta resultariam no gasto total com cada projeto. Evitou-se utilizar o termo custo até então, porque neste processo também seriam alocados gastos a projetos internos da empresa, de maneira que uma parcela do valor total dos projetos configuraria despesa, mesmo derivando de apontamentos de trabalho do pessoal da produção e do rateio de gastos dos departamentos produtivos. A Tabela 4 apresenta o resultado do custeamento de projetos e de clientes realizado para o mês de agosto de 2014 .

Tabela 4 - Custeamento de e projetos e clientes - agosto/2014

\begin{tabular}{|c|c|c|c|c|c|c|c|}
\hline Projeto & Cliente 1 & Cliente 2 & Cliente 3 & Cliente 4 & Cliente 5 & Interno & Total \\
\hline Projeto 01 & & & & & & $27.875,90$ & $27.875,90$ \\
\hline Projeto 02 & & & & $13.776,34$ & & & $13.776,34$ \\
\hline Projeto 03 & & & $3.567,84$ & & & & $3.567,84$ \\
\hline Projeto 04 & & & 90,57 & & & & 90,57 \\
\hline Projeto 05 & & & 71,46 & & & & 71,46 \\
\hline Projeto 06 & & & 734,14 & & & & 734,14 \\
\hline Projeto 07 & & & $1.922,73$ & & & & $1.922,73$ \\
\hline Projeto 08 & & & $4.309,55$ & & & & $4.309,55$ \\
\hline Projeto 09 & & & $3.447,47$ & & & & $3.447,47$ \\
\hline Projeto 10 & & 593,46 & & & & & 593,46 \\
\hline Projeto 11 & & $7.409,31$ & & & & & $7.409,31$ \\
\hline Projeto 12 & & & & & & $1.051,94$ & $1.051,94$ \\
\hline Projeto 13 & $1.433,43$ & & & & & & $1.433,43$ \\
\hline Projeto 14 & 999,54 & & & & & & 999,54 \\
\hline Projeto 15 & $2.898,80$ & & & & & & $2.898,80$ \\
\hline
\end{tabular}




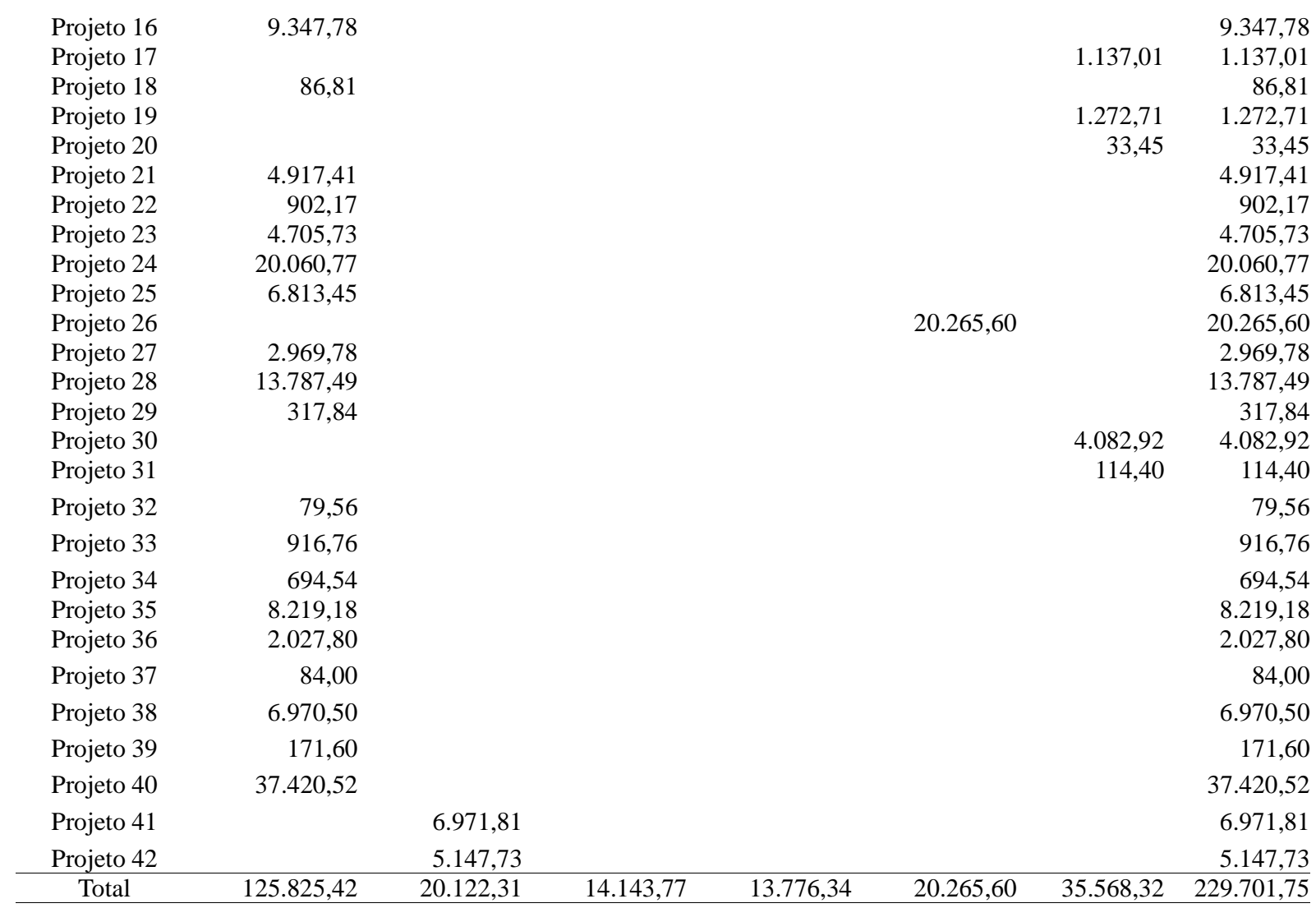

Fonte: Dados da pesquisa (2014).

Do total de gastos apropriados aos projetos, $\mathrm{R} \$ 194.133,43(85 \%)$ foram alocados a projetos de clientes, enquanto $\mathrm{R} \$ 35.568,32$ (15\%) foram alocados a projetos internos. Consequentemente, o primeiro montante foi classificado como custo e o segundo despesa do período.

\subsubsection{Controle e tomada de decisão}

Em termos de controle e apoio à tomada de decisão, a gestão de gastos proposta proporcionaria algumas informações importantes que não eram identificadas anteriormente, permitindo que a gestão como um todo, tanto da empresa quanto da holding, evoluísse em algumas análises. Em relação ao controle, a gestão de gastos proposta permitiria acompanhar a execução das horas de trabalho, conforme a previsão realizada para cada mês, e a consequente evolução dos valores orçados de custo da hora de trabalho da mão de obra direta. Alguns outros itens também poderiam a ser monitorados pela gestão de gastos da empresa, dentre eles: a proporcionalidade do valor das horas não produtivas sobre o total, o custo ocupacional por pessoa por departamento, o custo dos próprios departamentos, o custo dos projetos internos e o dispêndio de trabalho do pessoal da produção neste tipo de atividade. Adicionalmente, a proposta também permitiria a análise da composição dos gastos da empresa, identificando, por exemplo, a proporção dos custos ou despesas sobre o total, a proporção dos gastos fixos sobre as variáveis e a proporção dos gastos com mão de obra sobre os demais. 
Observa-se, também, que diversas informações estariam disponíveis para apoiar a tomada de decisão. A definição do preço das horas alocadas aos projetos, por exemplo, seria resultado das análises de custo médio por hora de trabalho para cada tipo de profissional da produção, adicionado-se o custo médio por hora recebido dos gastos fixos dos departamentos. Este valor deveria ser calculado de maneira que, ainda que houvesse alguma ociosidade, a receita da empresa fosse suficiente para cobrir tanto os seus custos quanto as suas despesas. No caso do mês estudado, fora os dados já apresentados, foram identificados alguns dos parâmetros de controle relacionados na Tabela 5.

Tabela 5 - Variáveis de controle - agosto/2014

\begin{tabular}{l|l|l}
\hline $\begin{array}{l}\text { Proporcionalidade das horas não } \\
\text { produtivas sobre o total }\end{array}$ & \multicolumn{2}{l}{$\begin{array}{l}6,94 \% \text { do total de horas de trabalho da mão de obra direta no período. } \\
15,77 \% \text { do valor total da mão de obra direta. }\end{array}$} \\
\hline $\begin{array}{l}\text { Custo ocupacional por pessoa e por } \\
\text { departamento }\end{array}$ & $\begin{array}{l}\text { Departamentos: administrativo, de desenvolvimento de } \\
\text { sistemas, de desenv. web, de design e de marketing }\end{array}$ & \multicolumn{2}{l}{$\mathrm{R} \$ 220,63$} \\
\cline { 2 - 3 } & Departamento de manutenção de sistemas & $\mathrm{R} \$ 383,62$ \\
\cline { 2 - 3 } & Departamento de suporte ao cliente & $\mathrm{R} \$ 295,97$ \\
\hline $\begin{array}{l}\text { Dispêndio de trabalho do pessoal da } \\
\text { produção em atividades internas }\end{array}$ & $14,35 \%$ das horas apontadas e não produtivas da mão de obra direta \\
\hline $\begin{array}{l}\text { Proporção dos custos e despesas sobre o } \\
\text { total }\end{array}$ & $\begin{array}{l}\text { Custos: } \\
\text { Despesas: }\end{array}$ & $\begin{array}{l}72,77 \%(\mathrm{R} \$ 194.133,43) \\
27,23 \%(\mathrm{R} \$ 72.659,80)\end{array}$ \\
\hline $\begin{array}{l}\text { Proporção dos gastos fixos e variáveis } \\
\text { sobre o total }\end{array}$ & $\begin{array}{l}\text { Fixos: } \\
\text { Variáveis: }\end{array}$ & $\begin{array}{l}36,56 \%(\mathrm{R} \$ 97.547,89) \\
63,44 \%(\mathrm{R} \$ 169.245,34)\end{array}$ \\
\hline $\begin{array}{l}\text { Proporção dos gastos com mão de obra } \\
\text { sobre o total }\end{array}$ & $\begin{array}{l}\text { Gasto total com mão de obra: } \\
\text { Demais gastos: }\end{array}$ & $\begin{array}{l}88,95 \%(\mathrm{R} \$ 237.315,83) \\
11,05 \%(\mathrm{R} \$ 29.477,40)\end{array}$ \\
\hline
\end{tabular}

Fonte: Dados da pesquisa (2014).

Em nível de holding, a partir do momento em que a gestão de projetos, alinhada com a gestão de gastos, passasse a desenvolver orçamentos razoáveis para os projetos a serem executados, as empresas da holding passariam a contar com uma informação fundamental para a decisão quanto a realização ou não desses projetos. Em alguns casos, inclusive, este conhecimento dos custos poderia subsidiar a tomada de decisão quanto à contratação dos serviços de outras empresas, em face à possibilidade de redução de custos globais (com o possível encerramento de determinados departamentos) ou à indisponibilidade de recursos físicos ou humanos para atender a todas as demandas.

\section{Conclusão}

Como visto na etapa de diagnóstico, a gestão de gastos anterior apropriava, por meio de rateio, todos os gastos às empresas pertencentes à holding que usufruíam de seus serviços. Esta abordagem apresentava uma série de pontos de melhoria e não cumpria plenamente com os objetivos de custeamento dos serviços prestados, de controle e de apoio à tomada de decisão. Para 
tanto, elaborou-se uma proposta de gestão de gastos que aumentaria o nível de precisão do custeamento realizado às empresas clientes, uma vez que dependeria menos de rateios arbitrários e que identificaria o custo de cada serviço prestado; que daria um tratamento adequado às horas não produtivas da mão de obra direta, com a sua clara identificação e maior acurácia na sua alocação; e que forneceria mais informações para o controle dos gastos e o apoio à tomada de decisão.

Destaca-se que, em ambos os casos, a qualidade das informações geradas pelo sistema de gestão, dependeria enormemente da qualidade nos apontamentos de trabalho pela mão de obra direta, visto que tanto pela metodologia anterior quanto pela proposta, a maioria dos gastos eram apropriados em função destes apontamentos. Entretanto, esta dependência, no segundo modelo, seria maior. Isto porque, pela abordagem anterior, bastava saber para qual empresa o trabalho tinha sido dedicado e as horas dedicadas às atividades internas eram desconsideradas. Na abordagem proposta, seria necessário identificar também a qual projeto este trabalho teria sido dedicado e erros no apontamento de atividades internas resultariam em variações do valor total de custos e despesas.

A implantação da proposta de gestão de gastos tornaria o processo relativamente mais complexo e trabalhoso. Entretanto, admitiu-se que este seria um sacrifício necessário e oportuno para a obtenção de informações mais precisas, além de também resolver uma questão interna de relacionamento comercial entre as próprias empresas da holding. Para trabalhos futuros, recomenda-se a análise comparativa entre implantação, neste tipo de empresa, de um modelo de gestão de gastos semelhante ao proposto neste estudo e um modelo baseado no custeio variável, buscando verificar o grau de distorção no resultado que seria causado pela ativação de custos fixos no custeio por absorção e o grau de simplificação do sistema que o custeio variável representaria.

\section{Abstract}

This study presents the results of structuring the management of the expenses incurred in a company that provides services of development and maintenance of softwares. This is a descriptive research, carried out through a case study, with a predominantly qualitative approach. Data were collected through semi-structured interviews and documents of the organization, analyzed through the descriptive analysis technique. Considering the peculiar characteristics of the companies that provide services with respect to cost accounting, a diagnosis of the expense management adopted by this company was made, once it organizes its activities predominantly by projects (service orders). It was analyzed how the company's expenses classification was done, what it was composed by and how the appropriation of the expenses was done in this company. Then, a proposal of expenses management was made, aiming at mitigating the deficiencies identified in the stage of diagnosing the expense management model adopted by the company. The proposal of expense management was based on adoption of absorption costing with departmentalization. Thus, the goal was to improve costing, controlling and the provision of information for decision making.

Keywords: expenses management; services; development and maintenance of softwares.

\section{Referências}


Associação Brasileira das Empresas de Software (ABES). Mercado Brasileiro de Software: panorama e tendências, 2014. São Paulo: ABES, 2014.

Associação para Promoção da Excelência do Software Brasileiro (SOFTEX). Software e Serviços de TI: A indústria brasileira em perspectiva. Campinas: Observatório SOFTEX, 2012.

Banco Nacional do Desenvolvimento (BNDES). Apoio financeiro: Porte de empresa. Disponível em: <http://www.bndes.gov.br/SiteBNDES/bndes/bndes_pt/Institucional/ Apoio_Financeiro/porte.html>. Acesso em: 05 out. 2014.

BRAGA, E. C. Gestão de custos através do custeio baseado em atividades (ABC): um estudo de caso em um projeto de desenvolvimento de software, Brasil. 124 f. Dissertação (Mestrado em Ciências Contábeis) - Faculdade de Administração e Finanças, Universidade do Estado do Rio de Janeiro, Rio de Janeiro, 2009.

CLEMENTE, A.; SOUZA, A. Gestão de custos nas empresas de desenvolvimento de software da região metropolitana de Curitiba. IX Congresso Internacional de Custos. Florianópolis, 2005.

CORRÊA, R. C. Custos em empresas prestadoras de serviços de informática: aplicação do ABC. Dissertação de Mestrado, PPGEP - Universidade Federal de Santa Catarina. Florianópolis, 2002.

CRUZ, J. L. dos S. Proposta de aplicação do método de custos ABC: Estudo de caso de uma empresa do ramo de desenvolvimento de software. 2011. 59 fls. Monografia (Curso de Graduação em Ciências Contábeis) - Departamento de Ciências Contábeis - Universidade Federal de Santa Catarina, Florianópolis, 2011.

DUARTE, D. Precificação convencional e precificação estratégica, reagir às condições do mercado ou gerenciálas de maneira proativa. 2009. 41 f. Monografia (Especialização) - Curso de Marketing, Universidade Candido Mendes, Rio de Janeiro, 2009.

GOMES, S. Um sistema de contabilidade por atividades para gestão de empresa de serviços em desenvolvimento de software. Tese de Doutorado, PPGEP - Universidade Federal de Santa Catarina. Florianópolis, 2004.

HANSEN, D. R.; MOWEN, M. M. Gestão de custos: contabilidade e controle. São Paulo: Pioneira Thomson Learning, 2003.

HORNGREN, C. T.; DATAR, S. M.; FOSTER, G. Contabilidade de custos. São Paulo: Pearson Prentice Hall, 2004.

Instituto Brasileiro de Geografia e Estatística (IBGE). Demografia das empresas, 2010. Rio de Janeiro: IBGE, 2012.

Pesquisa anual de serviços, 2010. Rio de Janeiro: IBGE, 2012.

. Pesquisa anual de serviços, 2011. Rio de Janeiro: IBGE, 2013.

KIRK, J.; MILLER, M. L. Reliability and validity in qualitative research: qualitative research methods series. Newbury Park: Sage, 1986.

LEONE, G. S. G. Contabilidade de custos. 3. ed. São Paulo: Atlas, 2009.

MAHER, M. Contabilidade de custos: criando valor para a administração. São Paulo: Atlas, 2001.

MALHOTRA, N. et al. Introdução à pesquisa de marketing. São Paulo: Prentice Hall, 2005.

MARINHO, S. V. Gestão de custos em empresas de desenvolvimento de software de santa catarina: uma pesquisa exploratória. Revista de Contabilidade do Mestrado em Ciências Contábeis da UERJ (online), Rio de Janeiro, v. 16, n. 3, p. 2-19, set./dez., 2011.

MARION, J. C. Contabilidade empresarial. São Paulo: Atlas, 2007.

MARTINS, E. Contabilidade de custos. São Paulo: Atlas, 2003.

OLIVEIRA, L. M. de. Contabilidade de custos para não contadores. São Paulo: Atlas, 2009.

SOUZA, R. A gestão dos custos através do custeio baseado em atividade: um estudo de caso em pequena empresa de serviço de suporte em informática. Dissertação de Mestrado, PPGEP - Universidade Federal de Santa Catarina. 
Florianópolis, 2002.

VALERIANO, D. Moderno gerenciamento de projetos. São Paulo: Pearson Prentice Hall, 2005.

VERGARA, S. C. Métodos de pesquisa em administração. São Paulo: Atlas, 2003.

Nome completo: Ricardo Kenji Fonseca

Filiação institucional: Universidade do Estado de Santa Catarina - UDESC

Departamento: Administração Empresarial

Função ou cargo ocupado: Estudante

Endereço completo para correspondência (bairro, cidade, estado, país e CEP): Av. Madre

Benvenuta, 2037 - Itacorubí - Florianópolis - SC - CEP 88.035-001.

Telefones para contato: $48-33218200$

e-mail: ricardokenji1@gmail.com

Nome completo: Fabiano Maury Raupp

Filiação institucional: Universidade do Estado de Santa Catarina - UDESC

Departamento: Administração Empresarial

Função ou cargo ocupado: Professor

Endereço completo para correspondência (bairro, cidade, estado, país e CEP): Av. Madre

Benvenuta, 2037 - Itacorubí - Florianópolis - SC - CEP 88.035-001.

Telefones para contato: $48-33218200$

e-mail: fabianoraupp@hotmail.com

Submetido em: 18-02-2015

Aceito em: 14-09-2015 